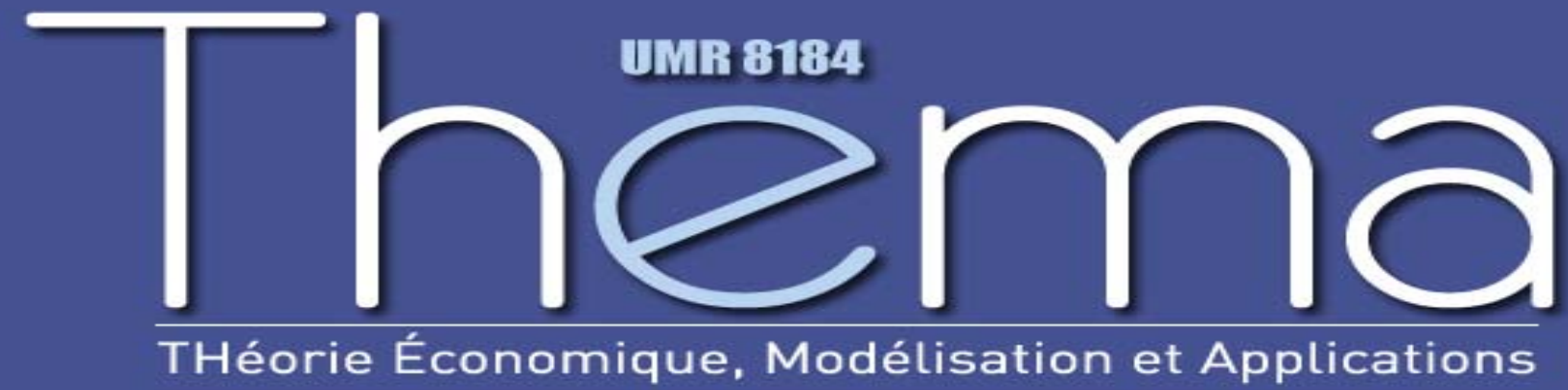

Thema Working Paper $n^{\circ} 2009-02$ Université de Cergy Pontoise, France

Commuting, Wages and Bargaining Power

Peter Rupert, Elena Stancanelli, Etienne Wasmer

February, 2009 


\title{
Commuting, Wages and Bargaining Power
}

\author{
Peter Rupert (University of California, Santa Barbara), \\ Elena Stancanelli (CNRS, THEMA, University Cergy) \\ Etienne Wasmer (Sciences-Po, OFCE, IZA and CEPR)
}

February 6, 2009

\begin{abstract}
A search model of the labor market is augmented to include commuting time to work. The theory posits that wages are positively related to commute distance, by a factor itself depending negatively on the bargaining power of workers. Since not all combinations of distance and wages are accepted, there is non-random selection of accepted job offers. We build on these ingredients to explore in the data the relationship between wages and commute time. We find that neglecting to account for this selection will bias downward the wage impact of commuting, and marginally affect the coefficients on education, age and gender. The correlation between the residuals of the selectivity equation and the distance equation is -0.70 , showing the large impact of commute time on job acceptance decisions. We also use the theory to calculate the bargaining power of workers which largely varies depending on demographic groups: it appears to be much larger for men than that for women and that the bargaining power of women with oung children is essentially zero.
\end{abstract}




\section{Introduction}

The job search model, based on the work of McCall-Mortensen-Pissarides, has become the workhorse to describe the outcome of decisions by workers and firms in terms of the aggregate labor market. Such models can be characterized by search and recruiting frictions and by the necessity of reallocating workers to jobs due to separations. As such, workers are willing to accept any job that pays a wage higher than their reservation wage. However, the wage is only one attribute of the decision to accept a job. We argue in this paper that commuting time or distance plays an important role in the decision to accept or reject a job.

Search theory has long recognized the role of geographical distance and commuting costs. Stigler (1961) argued that price ignorance was in large part due to geographical dispersion. Lucas and Prescott (1974) have a spatial dispersion of labor markets and there is a cost (a period of unemployment) of moving between islands are. Diamond (1981, 1982) introduces costs of making draws to get a new offer which is, implicitly or explicitly, a moving cost, i.e., the cost of finding a trading partner. Gaumont, Schindler, and Wright (2006) show that the introduction of commuting costs can resolve the Diamond Paradox, leading to a dispersion of wages. Wasmer and Zenou (2006) show that labor and housing markets interact when distance affects search efficiency. Manning (2003) uses the dependence of separations due to commute distance as evidence of monopsony power of employers, as wages do not fully reflect the cost of commuting. Van Ommeren, Van den

Berg, and Gorter (2000) estimate a structural search model with on-the-job mobility and identify the marginal cost of commuting time found to be approximately half of the hourly wage per hour of commute. Van den Berg and Gorter (1997) find that among demographic groups, females with children face a higher disutility of commuting, while being in a region with higher unemployment reduces this disutility parameter. Gautier and Zenou (2008) show that the cost and difficulty of black workers to buy a car leads to an amplification of spatial mismatch, that is, the difficulty of black workers to access jobs located in suburbs.

Despite these papers, there are very few search models in macroeconomic theory where commute costs play a central role. Rupert and Wasmer (2008) build the dual of a search and matching 
model, where random wage offers are replaced by random "commute-distance offers" and where workers can relocate at some cost to better locations. They argue that housing frictions differ across countries, and that cross-country differences in housing frictions can (i) explain large differences in geographical mobility between Europe and the US, and (ii) explain a significant part of the difference in unemployment rates.

In this paper, we document further the role of commute distance. First, we present some evidence showing the importance of commuting time. Second, we develop a simple theory of job offers in which jobs have two components: A productivity component and a commute distance component. We show reservation strategies and the role of distance in determining wages. Third, we document the correlation between wages and commute distance using a very detailed French time-use survey. Finally, we use the theory to measure the bargainaing power of workers.

In the model, workers have a reservation strategy where wages and commute distance matter: Accepted offers must generate a positive link between commute distance and wages. Productivity itself may depend on commute distance. That is, workers may be more tired from long commutes, thus generating a negative link between productivity and commute distance. Conversely, job offers located in more remote locations may be of higher productivity if workers' skills are heterogeneous and match productivity is idiosyncratic, as workers might target their job search to the most profitable areas when commutes are long.

The empirical results are as follows: We find that neglecting the commute distance equation in the estimates of wage equations seriously biases downward the wage impact of commute, and marginally affects the coefficient on education, age and gender. The correlation between the residuals of the selectivity equation and the distance equation is -0.70 , showing the large impact of commute time on job acceptance decisions. We also derive a formula linking bargaining power and the coefficients of the wage equation and find that the overall bargaining power of workers is 0.42 on average with large heterogeneity: 0.73 for men, 0.15 for women and almost zero for women with young kids. 


\section{Commuting}

In this paper, we argue that commuting distance plays an important role when deciding whether to accept a job. Table 1 reports data from a European-wide panel (the ECHP panel 1994-2001) for a sample of currently unemployed job seekers. ${ }^{1}$ These individuals received a job offer during the past 4 weeks and rejected it.

Table 1: Reasons for Rejecting Offers

\begin{tabular}{lcccc}
\hline \hline & $\%$ & $\begin{array}{c}\text { \% excl. } \\
\text { last } 3\end{array}$ & $\begin{array}{c}\text { \% excl. } \\
\text { last } \mathbf{3} \text { \& hrs }\end{array}$ & $\begin{array}{c}\text { \% compared } \\
\text { to wage rate }\end{array}$ \\
\hline 1. rate of pay & 12.1 & 21.8 & 24.7 & 59.7 \\
2. temporary/insecure job & 6.65 & 12.0 & 13.6 & - \\
3. type of work & 12.9 & 23.3 & 26.4 & - \\
4. number of working hours & 6.05 & 11.0 & - & - \\
5. working time (day time, night time, shifts...) & 6.42 & 11.6 & 12.4 & - \\
6. working conditions / environment & 3.06 & 5.54 & 6.27 & - \\
7. distance to job / commuting & $\mathbf{8 . 1 4}$ & $\mathbf{1 4 . 7}$ & $\mathbf{1 6 . 7}$ & $\mathbf{4 0 . 3}$ \\
8. could not start the job at required time & 4.82 & - & - & - \\
9. other reasons for not accepting & 20.99 & - & - & - \\
10. not yet decided & 18.93 & - & - & - \\
Sum & 100 & 100 & 100 & 100 \\
\hline
\end{tabular}

Commute distance matters and will be shownn int.....

Column 1 of Table 1 shows that roughly $40 \%$ of individuals have not decided or don't report a good reason (reasons 8 and 9). Column 2 excludes those individuals and those who are not immediately available, thus revealing that $14.7 \%$ of job offers were turned down due to commute distance; $16.7 \%$ if one further excludes the jobs rejected due to the offered number of hours. Finally, the last column indicates that the impact of commute distance is roughly a third lower than the impact of the wage rate when the job acceptance decision has to be made.

\footnotetext{
${ }^{1}$ Those having no job and are looking for one or are currently working less than 15 hours and looking for an additional one or a different one.
} 


\section{Model}

\subsection{Standard search setup}

In the standard search model à la McCall, workers decide whether to accept a job offer based on the wage they get and the distribution of the known potential wage offers. The decision to work is based on a comparison of the value of being in an employment relationship to the value of remaining unemployed. In a continuous time setup, the canonical job-search model can be summarized as:

$$
\begin{aligned}
r U & =b+\lambda \int \operatorname{Max}\left(0, E\left(w^{\prime}\right)-U\right) d F(w) \\
r E(w) & =w-C(h)+\delta(U-E),
\end{aligned}
$$

where $r$ is the rate of interest, $b$ is the value of unemployment benefits, $\lambda$ is the arrival rate of job offers, $\delta$ is an exogenous job destruction rate, $F$ is the c.d.f. of wage offers, $C(h)$ is the cost of working $h$ hours (assumed to be fixed due to some indivisibility) and $E$ and $U$ are the presentdiscounted values of being employed and unemployed, respectively.

Noting that equation Eq. (1) is increasing in $w$ with constant slope $1 /(r+\delta)$ leads to

$$
E(w)-U=\frac{w-w^{R}}{r+\delta}
$$

The positive slope implies that there is a well-defined reservation rule $w^{R}$, which can be defined implicitly by $U=E\left(w^{R}\right)$, that is

$$
w^{R}=b+C(h)+\frac{\lambda}{r+\delta} \int_{w^{R}}^{+\infty}\left(w-w^{R}\right) d F(w) .
$$

Knowledge of the reservation wage, $w^{R}$, has implications for the rate of unemployment, given by:

$$
u=\frac{\delta}{\delta+\lambda\left[1-F\left(w^{R}\right)\right]}
$$




\subsection{An augmented setup}

In this section we augment the standard search environment to include commuting time (distance). A job is assumed to be a package $\left(w^{d}, d\right)$ where $d$ is a commute distance. The disutility cost of commuting is not a perfect substitute for hours of work and therefore we assume $C(h, d)$ with $\partial C / \partial d>0$ and $\partial^{2} C / \partial d^{2}>0$. We then have:

$$
\begin{aligned}
r U & =b+\lambda \int \operatorname{Max}\left(0, E\left(w^{\prime}, d^{\prime}\right)-U\right) d F(w, d) \\
r E(w, d) & =w-C(h, d)+\delta(U-E)
\end{aligned}
$$

Since $\partial E / \partial w$ is positive, and $\partial E / \partial d<0$, we have the following reservation strategies. There exists a function $w^{R}(d)$ which defines the reservation wage for any distance, and we have $w^{R \prime}(d)>$ 0 ; alternatively, there exists a reservation distance $d^{R}(w)$ such that $d^{R \prime}(w)$ is positive. Note also that $d^{R}(w)^{-1}=w^{R}(d)$. Finally, since

$$
E(w, d)-U=\frac{w-w^{R}(d)}{r+\delta}
$$

we have, for all $d$, the indifference condition $E\left(w^{R}(d), d\right)=U$ which defines a curve in $(w, d)$ space. The job acceptance frontier is given as,

$$
w^{R}(d)=b+C(h, d)+\frac{\lambda}{r+\delta} \int_{0}^{+\infty} \int_{w^{R}(d)}^{+\infty}\left(w^{\prime}-w^{R}\left(d^{\prime}\right)\right) d F_{d}(w) d G(d),
$$

where $F_{d}$ is the conditional distribution function (c.d.f.) of wage offers given distance and $G$ is the c.d.f. of commute distances.

From this formula, one can derive the slope of the wage/distance relationship along the acceptance curve; differentiating with respect to $d$ :

$$
w^{R \prime}(d)=\frac{\partial C(h, d)}{\partial d}-\frac{\lambda}{r+\delta} \int_{0}^{+\infty} \int_{w^{R}(d)}^{+\infty} w^{R \prime}\left(d^{\prime}\right) d F_{d}(w) d G(d)
$$

Figure 1 shows the job acceptance curve and the productivity of a match. 
Figure 1: Job Acceptance

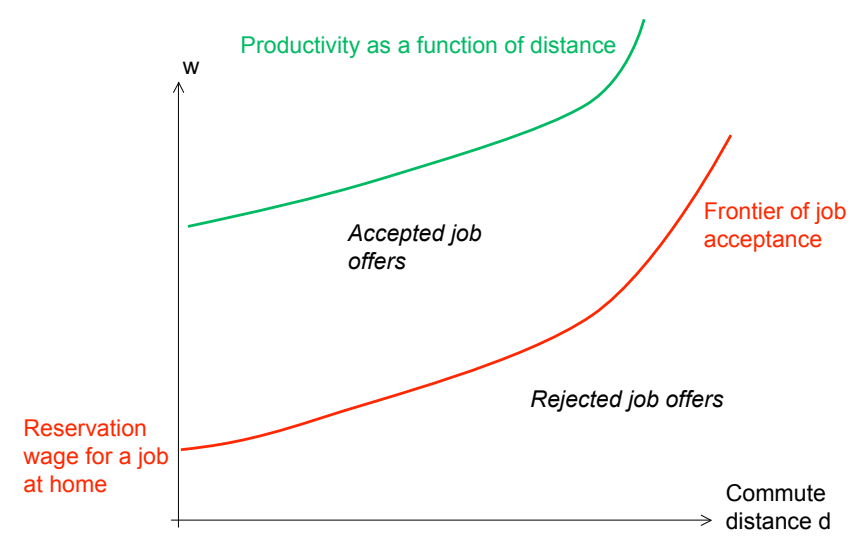

In the special case where $C$ is increasing and linear in $d, w^{R \prime}$ has a constant slope:

$$
w^{R \prime}=\frac{\partial C(h, d)}{\partial d} \frac{1}{1-\frac{\lambda}{r+\delta} \bar{a}} \text { where } 0<\bar{a}<1 \text { is the average acceptance rate. }
$$

\subsection{Extension: bargaining and commuting}

Extending the framework to deal with bargaining is straightforward. Assume that workers draw a productivity-distance pair, $(y, d)$, where $y$ is productivity. The surplus of the firm is given by

$$
J(y, d)=\frac{y-w(y, d)}{r+\delta} .
$$

The Bellman equations for unemployed and employed workers are as follows:

$$
\begin{aligned}
r U & =b+\lambda \int \operatorname{Max}\left(0, E\left(y^{\prime}, d^{\prime}\right)-U\right) d F(y, d) \\
r E(y, d) & =w(y, d)-C(h, d)+\delta(U-E) .
\end{aligned}
$$

From Eq. (10) we have

$$
E(y, d)-U=\frac{w(y, d)-C(h, d)-r U}{r+\delta}
$$


We also assume, consistent with search-matching theory, that firms and workers bargain over wages as long as there is positive surplus. The bargaining equation solves

$$
\beta J(y, d)=(1-\beta)(E-U)
$$

leading to

$$
w(y, d)=(1-\beta) r U+(1-\beta) C(h, d)+\beta y .
$$

Partial differentiation of the wage equation implies the following results:

$$
\frac{\partial w}{\partial y}=\beta \text { and } \frac{\partial w}{\partial d}=(1-\beta) \frac{\partial C}{\partial d}
$$

As in the previous section, there exists a well defined reservation strategy. Noting that

$$
\begin{aligned}
& \frac{\partial E}{\partial y}=\frac{\beta}{r+\delta} \\
& \frac{\partial J}{\partial y}=\frac{1-\beta}{r+\delta}
\end{aligned}
$$

and given the monotonicity of asset values, there exists a reservation productivity $y^{R}(d)$. Given the constant slopes calculated above, we have that

$$
\begin{aligned}
E(y, d)-U & =\beta \frac{y-y^{R}(d)}{r+\delta} \\
J(y, d) & =(1-\beta) \frac{y-y^{R}(d)}{r+\delta} .
\end{aligned}
$$

Finally, $y^{R}(d)$ can be recovered from the fact that workers are indifferent between working and not working when productivity is equal to the reservation value, that is:

$$
r E\left(y^{R}(d), d\right)=r U
$$

Therefore, $r U$ is given as:

$$
r U=b+\lambda \int \operatorname{Max}\left(0, E\left(y^{\prime}, d^{\prime}\right)-U\right) d F(y, d)=r E\left(y^{R}(d), d\right)=w(y, d)-C(h, d)+\delta(U-E)
$$


or, after reorganizing terms:

$$
\left.y^{R}(d)=b+C(h, d)+\frac{\beta \lambda}{r+\lambda} \int_{0}^{+\infty} \int_{y^{R}(d)}^{+\infty}\left(y^{\prime}-y^{R}\left(d^{\prime}\right)\right) d F_{d}(w) d G(d)\right]
$$

which is similar to (6).

Proposition 1. Commute distance affects wages: $\frac{\partial w}{\partial d}=(1-\beta) \frac{\partial C}{\partial d}$.

The proposition states that workers receive higher compensation for commute costs if their bargaining power is lower. Note that commute costs appear in the wage equation with weight $(1-\beta)$. This is due to the fact that the commute costs are on the "reservation-wage side". The term $r U+C(h, d)$ is the opportunity cost of working. The bargained wage is a weighted average of opportunity cost and the productivity of the match, $y$. Therefore, the higher the bargaining power, the closer the wage to the productivity of the match and the further away from the opportunity cost: the effect of commute costs vanishes when $\beta$ goes to 1 .

\section{Wage equations with commute distance}

The central idea of our approach is that because wages and commutes are only observed for those accepting a job, not accounting for selection will give biased estimates. Therefore, we will provide a generalization of Heckman selection methods to examine the effect of commuting distance on wages. We also estimate the reservation strategy of agents, using a stochastic frontier method.

\subsection{Conditional Mixed Process Estimates: method}

We use a simultaneous equations approach to estimate the observed (accepted) wages, the observed (accepted) commuting time and a selection equation, to control for the fact that wages and commuting time are oberved only for people that are employed, ie. that received a job offer and accepted it. Therefore, we estimate a conditional (recursive) mixed process model. That is, a simultaneous equation system where the different equations can have different kinds of dependent variables. To be more precise, recall that jobs are characterized in terms of the wage they offer 
and the implied commuting distance and that the probability of receiving a job offer is $\lambda$. Therefore, the reservation wage will also be a function of commuting distance. In particular, reservation wages are increasing in commuting distance under sticky housing markets. In this paper we do not have access to reservation wage information. Therefore, we use data on accepted wages, $w$, with the implied commuting distance, $d$, conditional on employment, to estimate the relation between commuting distance, wages and the employment probability. ${ }^{2}$

Formally, the employment probability, $\theta$, can be written as the product of the probabilities of receiving a job offer and accepting it:

$$
\theta=\lambda\left[1-F\left(w^{R}(d)\right)\right]
$$

where $F()$ is the conditional distribution of wages. Thus, commuting distance enters the structural probability Eq. (21) because of its effect on the reservation wage, which, in turn, affects the acceptance probability.

We assume that the wage offer distribution and the distribution of distance offers are a function of individual and match specific characteristics, is lognormal and specified as:

$$
w_{i}=g\left(d_{i}\right)+\beta^{\prime} X_{i}+\gamma^{\prime} Z_{i}+\varepsilon_{i}, \quad \varepsilon_{i} \sim N\left(0, \sigma_{\varepsilon}^{2}\right)
$$

where $X_{i}$ is a vector containing individual characteristics and $Z_{i}$ a vector of match characteristics. We test whether the functional form of $g$ should be specified as a quadratic to allow for non-linearities. The error term $\varepsilon_{i}$ may represent approximation error, measurement error and randomness in preferences.

To allow for possible correlation of commuting distance with the error of other equations, an equation for commuting distance is specified as:

$$
d_{i}=\mu^{\prime} q_{i}+v_{i}, \quad v_{i} \sim N\left(0, \sigma_{v}^{2}\right),
$$

\footnotetext{
${ }^{2}$ Reservation wages are rarely observed in the data, exceptions are, for example, Bloemen and Stancanelli (2001), that used subjective reservation wages in an extended search model.
} 
where $q$ includes individual characteristics.

Accepted wages, with the implied commuting distance, are only observed for employed individuals, thus we condition on employment by simultaneoulsy specifying an equation for the employment probability -which is equivalent to the job acceptance probability. The underlying equation for employment is:

$$
\theta_{i}^{*}=m^{\prime} k_{i}+e_{i} \quad e_{i} \sim N\left(0, \tau^{2}\right)
$$

where $k_{i t}$ are individual characteristics and $\theta_{i}=1$ if $\theta_{i}^{*}>0 ; \theta_{i}=0$, otherwise.

We assume joint normality of the error terms of the employment equation, the equation for wages and the equation for commuting distance. We define $\rho_{e w}$ as the correlation coefficient between the errors of the employment equation $e_{i t}$ from Eq. (24) and the errors $\varepsilon_{i t}$ of the wage equation Eq. (22); $\rho_{e d}$ as the correlation coefficient between the errors of the employment equation and the errors of the equation for commuting distance $v_{i, t-1}$ from Eq. (23), and $\rho_{d w}$ as the correlation between wages and commuting distance.

Under the assumption of joint normality, the employment probability, conditional on the commuting distance and the wage, can be written as:

$$
\Phi\left(\frac{m^{\prime} k_{i t} \psi_{e \mid \varepsilon, v}}{\sigma_{e \mid \varepsilon, v}}\right)
$$

where $\Phi($.$) is the standard normal distribution function and use has been made of the normality$ of the distribution of the errors of the employment equation, conditional on commuting distance and wages. $\psi\left(e_{i t} \mid \varepsilon_{i t}, v_{i, t-1}\right)$ is the conditional mean of the error term of the employment equation (conditional on the errors of commuting time and wages) $; \sigma_{e \mid \varepsilon, v}$ is the conditional variance of the error term of the employment equation (conditional on the errors of commuting time and wages).

For each individual, the likelihood contribution is obtained by multiplying the employment probability by the joint density of commuting and wages. 


\subsection{Data description}

The data for the analysis are drawn from the 1998-99 French time-use survey (Enquête Emploi du temps), carried out by the National Statistical Office (INSEE). This is a cross-sectional dataset, providing us with information on individual employment, wages and commuting time. The survey covers about 8,000 representative households, and includes over 20,000 individuals of all ages, from 0 to 103 years. Three questionnaires were collected: a household questionnaire, an individual questionnaire and the time diary. The diary was collected for all individuals in the household, and was filled in for one day, chosen by the interviewer, and could be either a weekday or a weekend day.

The individual questionaire also contains a recall question on usual commuting time. Therefore, an advantage of this dataset is that we can compare commuting time reported from the recall question with commuting time from the daily diary. It is well-known that recall information is bound to be less precise. On the other hand, people are likely to know extremely well how much time on average they spend commuting every day, so that recall bias is unlikely to be very important for commuting information. Instead, the diary information on commuting is more likely to be affected by random variation in commuting, such as, for example, traffic jams. Besides, the day the diary is collected could fall on a day when people do not work for part-timers or if the diary is collected on a weekend day. There is also information on their main place of work, which allows us to determine if an individual's main job is in their home, in which case their commuting time is set to zero.

Another advantage of the survey is that it collects earnings information in addition to contractual hours of work. Total household income is asked, though in brackets. ${ }^{3}$ The data also contains detailed information on individual educational attainment, age, and sex, which we also use in our model.

Other variables in the data set allow us to control for factors that might affect mobility, such as

\footnotetext{
${ }^{3}$ We tried two different specifications for wages: monthly earnings and the hourly wage; however, we generally report only the specifications with monthly earnings as the results are more or less equivalent since we have selected a sample of full-time workers.
} 
Table 2: Sample Selection Criteria

\begin{tabular}{lr}
\hline Criterion applied & Observations \\
\hline Single people living on their own or in a couple & 13473 \\
Employed, unemployed or housewives & 9251 \\
Age less than 60 years & 8665 \\
\hline
\end{tabular}

home ownership, duration of occupation of the residence -which we interact with home ownershipmarital status and presence and age of children.

We select a sample of individuals according to the following criteria:

- single people living on their own or people living as a couple, either married or cohabiting;

- employed; unemployed; housewives/househusbands (We dropped only retirees, those in fulltime education, military personnel and the disabled).

- aged less than sixty years.

Information on monthly gross earnings in the year of the survey was collected both as a continuous variable and in intervals for respondents who did not provide continuous earnings information. For them, as noted above, we do not compute hourly wages. To construct the hourly wage rate, we consider only observations providing information on continous wages and usual hours of work (roughly half of those who reported earnings). Total household income was set equal to the mid point of each interval; and to the threshold level for individuals in the top income interval. Non-labour income was constructed by subtracting own earnings from the total household income variable. Therefore, non-labour income includes earnings of the spouse, if any. All earnings and income information in the survey was collected in French Francs (equal to 1/6.55957 Euros). Thus, hourly wages are measured in French Francs; but we transform them to Euros, to make the results more readable.

We have included dummy variables for education, with the omitted category being individuals with less than elementary schooling. We also use a series of variables to control for occupation types, sector and size of firm. 
We also control for the size of the area where people reside with a series of dummies as follows: Paris; suburbs (outskirts) of Paris (banlieue, in French); cities of of over 50,000 inhabitants ; cities of 20,000 to 50,000 inhabitants; small cities of less than of 20,000 inhabitants; rural neighborhoods. Regional dummies are also included.

Home ownership is a dichomotomous variable equal to one for individuals that own their place of residence. We also have information in the data on duration of occupancy of the place where people reside, in years. We have constructed two variables by interacting the duration of occupancy of the residence with the house ownership dummy: Duration of occupancy of the place where people reside, in years, for people that rent their residence place; duration of occupancy of the place where people reside, in years, for people that own their residence place. It may be that people that live longer in a place to be less willing to move and this effect is likely to be stronger for individuals that own their place of residence.

The marital status dummy is equal to one for married people and to zero for cohabiting or single people. We consider cohabiting couples as such for several reasons. First, they are subject to the same income taxation scheme as single people, while married people are taxed jointly. Second, cohabiting women have participation rates very close to those of single women and much higher than those of married women. We constructed a dummy variable for the presence of young children aged less than three in the household. This is the interesting threshold to look at as $99 \%$ of children aged three and above go to school in France. Maternelle (pre-school) school for children aged three to five is free of charge and open from early morning to six in the afternoon. The number of children aged less than eighteen is also entered among the explanatory variables.

As noted above, the diary day was chosen by the interviewer. Activities were recorded every ten minutes over a 24-hour period. Both main and secondary activities were coded. These latter are activities carried out simultaneously, such as cooking and watching the children, with the respondent deciding which activity was primary and which secondary. There were approximately 140 main activity categories and 100 secondary activity categories were defined by the survey designers. Interestingly, all commuting time to work was reported as main activity. Commuting time 
to work is coded in minutes.

Descriptive statistics for the full sample are provided in Table 3. Over 50\% of the sample is composed of people that own their residence. The average duration of occupancy of their residence is about ten years, whether people own it or not. This is slightly larger for women than for men.

Women in full-time employment are, on average, slightly less educated than men. On the other hand, more women than men have completed secondary education. Average years of schooling of men and women are the same and equal to just over ten years. The average monthly earnings of women are almost three hundred Euros less than those of men; and the hourly wage is 2 Euros smaller.

Commuting time is on average about 45 minutes per day, irrespective of gender. The diary information records shorter commuting time: forty minutes instead of fifty, according to the recall question; and slightly less for women than for men. About $24 \%$ of the respondents in the sample reported to be tired from commuting at the end of the day.

Table 4 provides the distribution of monthly earnings and commuting time for the recall question and the diary. The distribution of commuting time looks quite skewed. The lowest decile of the distribution of commuting time of full-time workers, spend less than ten minutes travelling to their workplace and back. The median full-time worker in the sample commutes forty minutes per day, while people in the third quartile commute one hour; and those in the top decile, over two hours. The lower-educated people tend to commute a little less than the higher-educated. Married women in full-time employment commute less time at all percentiles of the distribution of commuting time than the sample worker.

Table 5 shows the mode of transportation of full-time workers in the sample. Over $70 \%$ of people travel to work by car. This proportion is slightly larger for men, 74\%, than for women, $72 \%$. Instead, travelling to work by bus is more common for women, over $9 \%$, than for men, $6 \%$. Interestingly, almost twice as many women than men go to work on foot $(9.2 \%$ against $5.6 \%)$; while ten times more men than women use their bycicle or the motorbycicle (almost 3\% against $0.6 \%$, for either bycicle or motorbycicle). The differences by gender are smaller for the train (over 
Table 3: Summary Statistics-Full Sample

\begin{tabular}{|c|c|c|c|c|c|c|}
\hline \multirow[t]{2}{*}{ Variable } & \multicolumn{2}{|c|}{$\begin{array}{l}\text { Estimation sample } \\
\qquad N=8665\end{array}$} & \multicolumn{2}{|c|}{$\begin{array}{l}\text { Men } \\
\qquad N=42\end{array}$} & \multicolumn{2}{|c|}{$\begin{array}{l}\text { Women } \\
\qquad N=4645\end{array}$} \\
\hline & Mean & Std Dev & Mean & Std Dev & Mean & Std Dev \\
\hline Age & 41.14 & 9.52 & 41.48 & 9.26 & 40.83 & 9.74 \\
\hline Elementary schooling CEP & 0.10 & 0.30 & 0.08 & 0.27 & 0.11 & 0.32 \\
\hline Lower Secondary tech. bepc & 0.08 & 0.27 & 0.06 & 0.24 & 0.09 & 0.29 \\
\hline Lower Secondary cap-bep & 0.30 & 0.46 & 0.35 & 0.48 & 0.26 & 0.44 \\
\hline Upper Secondary tech bactech & 0.06 & 0.23 & 0.06 & 0.24 & 0.05 & 0.22 \\
\hline Upper Secondary bac & 0.08 & 0.27 & 0.06 & 0.23 & 0.09 & 0.29 \\
\hline Short Univ degree bac+2 & 0.12 & 0.32 & 0.11 & 0.31 & 0.13 & 0.34 \\
\hline Univ degree $>$ bac +2 & 0.12 & 0.32 & 0.14 & 0.34 & 0.10 & 0.30 \\
\hline School years & 10.15 & 4.34 & 10.30 & 4.43 & 10.02 & 4.44 \\
\hline Married & 0.68 & 0.47 & 0.69 & 0.46 & 0.69 & 0.47 \\
\hline Cohabiting & 0.17 & 0.37 & 0.18 & 0.38 & 0.16 & 0.37 \\
\hline No. of children & 1.30 & 1.22 & 1.30 & 1.23 & 1.29 & 1.21 \\
\hline Children, age $<3$ & 0.13 & 0.34 & 0.14 & 0.34 & 0.13 & 0.34 \\
\hline Ile de France & 0.19 & 0.39 & 0.19 & 0.39 & 0.19 & 0.39 \\
\hline \multicolumn{7}{|l|}{ Cities $>=20,000$ inhabitants } \\
\hline Small city $<20,000$ inhabitants & 0.17 & 0.37 & 0.17 & 0.37 & 0.17 & 0.37 \\
\hline Rural neighborhood & 0.26 & 0.44 & 0.26 & 0.44 & 0.25 & 0.43 \\
\hline Paris & 0.03 & 0.17 & 0.03 & 0.17 & 0.03 & 0.18 \\
\hline Outskirts of Paris & 0.13 & 0.33 & 0.13 & 0.34 & 0.13 & 0.34 \\
\hline French nationality & 0.94 & 0.24 & 0.94 & 0.24 & 0.94 & 0.23 \\
\hline Working mainly at home & 0.13 & 0.34 & 0.12 & 0.33 & 0.14 & 0.35 \\
\hline House ownership & 0.57 & 0.49 & 0.57 & 0.49 & 0.57 & 0.49 \\
\hline Dur. occup. residence, years & 9.78 & 9.13 & 9.48 & 9.04 & 10.05 & 9.20 \\
\hline Monthly Salary, Euros & 1338.60 & 746.45 & 1557.02 & 806.69 & 1111.16 & 598.83 \\
\hline Non labour income, monthly, Euros & 2070.75 & 1335.44 & 2109.36 & 1359.83 & 2036.03 & 1312.32 \\
\hline Hourly wage, Euros & 9.08 & 5.61 & 9.79 & 5.85 & 8.32 & 5.24 \\
\hline Contractual weekly hours & 35.75 & 7.76 & 37.93 & 5.57 & 33.12 & 8.98 \\
\hline Commuting time minutes, recall & 44.79 & 45.21 & 46.44 & 46.51 & 42.94 & 43.63 \\
\hline Commuting time minutes, diary & 27.22 & 42.93 & 34.49 & 48.07 & 20.80 & 36.64 \\
\hline Tired fom commuting, yes $==1$ & 0.16 & 0.37 & 0.17 & 0.37 & 0.16 & 0.36 \\
\hline
\end{tabular}


Table 4: Distribution of commuting time for the estimation sample

\begin{tabular}{|c|c|c|c|}
\hline Percentiles & hourly wage & commuting recall & commuting diary \\
\hline Full sample, obs. & 3693 & 4311 & 4178 \\
\hline $1 \%$ & 2.91 & 0 & 0 \\
\hline $5 \%$ & 4.51 & 0 & 0 \\
\hline $10 \%$ & 4.87 & 0 & 0 \\
\hline $25 \%$ & 5.86 & 10 & 0 \\
\hline $50 \%$ & 7.49 & 30 & 20 \\
\hline $75 \%$ & 10.42 & 60 & 60 \\
\hline $90 \%$ & 14.66 & 105 & 90 \\
\hline $95 \%$ & 19.54 & 120 & 120 \\
\hline $99 \%$ & 31.08 & 180 & 200 \\
\hline Up to elementary school, obs. & & 879 & 834 \\
\hline $1 \%$ & 2.06 & 0 & 0 \\
\hline $5 \%$ & 3.61 & 0 & 0 \\
\hline $10 \%$ & 4.40 & 0 & 0 \\
\hline $25 \%$ & 5.04 & 10 & 0 \\
\hline $50 \%$ & 6.05 & 30 & 20 \\
\hline $75 \%$ & 7.22 & 60 & 60 \\
\hline $90 \%$ & 9.52 & 90 & 90 \\
\hline $95 \%$ & 11.28 & 120 & 120 \\
\hline $99 \%$ & 20.10 & 210 & 200 \\
\hline University degree and above, obs. & & 1150 & 1119 \\
\hline $1 \%$ & 4.22 & 0 & 0 \\
\hline $5 \%$ & 5.59 & 0 & 0 \\
\hline $10 \%$ & 6.54 & 5 & 0 \\
\hline $25 \%$ & 8.57 & 20 & 0 \\
\hline $50 \%$ & 11.30 & 40 & 20 \\
\hline $75 \%$ & 16.24 & 70 & 60 \\
\hline $90 \%$ & 23.45 & 120 & 100 \\
\hline $95 \%$ & 28.87 & 140 & 120 \\
\hline $99 \%$ & 41.50 & 210 & 200 \\
\hline Married Women, obs. & & 1286 & 1247 \\
\hline $1 \%$ & 2.08 & 0 & 0 \\
\hline $5 \%$ & 4.04 & 0 & 0 \\
\hline $10 \%$ & 4.64 & 0 & 0 \\
\hline $25 \%$ & 5.41 & 10 & 10 \\
\hline $50 \%$ & 7.04 & 30 & 30 \\
\hline $75 \%$ & 9.67 & 60 & 60 \\
\hline $90 \%$ & 13.62 & 90 & 90 \\
\hline $95 \%$ & 19.02 & 120 & 120 \\
\hline $99 \%$ & 20.90 & 180 & 180 \\
\hline $\begin{array}{l}\text { Hourly wages are measured in Eur } \\
\text { Diary commuting is shown for ind } \\
\text { commuting information and that }\end{array}$ & $\begin{array}{l}\text { S. Commuting } \\
\text { jiduals that als } \\
\text { re employed. }\end{array}$ & $\begin{array}{l}\text { ime in minutes. } \\
\text { provided recall }\end{array}$ & \\
\hline
\end{tabular}


$1 \%$ for either gender) and the metro (3\% for men and $4 \%$ for women).

Table 5: Mode of Transportation to Work, $\%$

\begin{tabular}{lrrr}
\hline & Sample & Men & Women \\
\hline On foot & 7.25 & 5.59 & 9.22 \\
Bycicle & 1.81 & 2.10 & 1.47 \\
Motorbike & 1.81 & 2.82 & 0.61 \\
Car & 73.34 & 74.41 & 72.06 \\
Train & 1.64 & 1.79 & 1.47 \\
Metro & 3.92 & 3.49 & 4.44 \\
Bus & 7.81 & 6.02 & 9.44 \\
Other & 2.41 & 3.78 & 0.79 \\
\hline Sample size & 6398 & 3470 & 2928 \\
\hline
\end{tabular}

\subsection{Identification}

The identification is as follows: we expect non-labour income -set equal to total household income minus own earnings- to affect the employment decision but not the wages or the commuting time equation. Next, we assume that the size of the area of residence affects the transportation landscape and therefore the distance equation; but not the employment or wage equations. Instead, regional dummies enter all equations as they assumed to measure not only job availability -and thus the selection into employment- but also different wage premia and transport infrastructure.

We also use the duration of occupation of the place of residence to identify the commuting equation and the employment equation. Indeed, individuals that live longer in a given place may be less willing to move, as the costs of moving are likely higher for them. This can affect both the job acceptance probability -and therefore the selection into employment- and the distance travelled to work. In particular, we use two separate variables, one for the duration of occupation of the place of residence for renters; and the other for houseowners, both measured in years. We also assume that the number of children and the presence of small children affect accepted commuting time and employment, but not wages. Instead, gender and marital status enter all three equations, 
in the form of a dummy for being a woman and an interaction variable of being a woman and being married, to capture differences across all women and married women, in addition to gender effects.

We identify wages using information on the number of years of work experience. Finally, we enter a quadratic term in linear commuting time in the wage equation. Schooling years affect selection and wages but do not impact on commuting distance (we tested for their inclusion in the distance equation but in line with our expectations, the coefficient was not statistically significant). In order to avoid having to estimate a singular system, we present a wage equation which does depend on commute distance, but a commute distance equation which only depends on individual and firm's characteristics.

\subsection{Findings}

The results are given in Table 6. Observed wages increase with commuting time, though at a decreasing rate. The correlation coefficients of the three equations are statistically significant, with a large negative value between the residuals of the employment and the distance equation which is equal to -0.70 . This is rather intuitive: when worker receive a high distance offer, they are much less likely to accept the package (wage, distance) and therefore more likely to reject the offer. This tends to suggest that ignoring the selection due to commute distance biases the estimates of the effect of distance on wages (see below).

Women earn less by $11.1 \%$ but their marital status does not affect hourly wages. This might

be due to the fact that all women suffer the same wage penalty as if they were married; that is, employers may anticipate that single women will marry. We find that wages and employment increase with education years (schooling years, each additional raising wage by $5.86 \%$ ). Under this specification, wages and employment increase with age at a decreasing rate; while the reverse age pattern applies to commuting time -commuting time falls with age at an increasing rate.

Interestingly, both the number of children and the presence of small children negatively affect the employment selection, as expected -at least for women, but they impact positively on commuting time. This may indicate that people with small children are prepared to commute further away 
and are less willing to move closer to their job.

Finally, the main effect of commute on wages is quite large. We find that the linear coefficient of hours of commute is almost a third $(+0.327)$, with a quadratic term equal to $-4.18 \%$. This means that an hour of commute is compensated by a $28.5 \%$ increase in wages.

In columns 4 to 5, we report the traditional Heckman selection model where we add commute hours but do not have a commute time equation. In that case, as well as in column 6 where we report a simple OLS of wages, the effect of commute time on wages is much smaller, between 8.4 and 9.0 percent. This suggests that, due to the strong correlation between the residuals of the commute time equation and the other equations, ignoring the selectivity in commute time bias the estimate of the Mincerian wage equation quite seriously.

The estimates of the recursive system equations (columns 1-3) have a few differences with traditional Heckman (col 4-5) and OLS (col 6) in terms of the effects of other variables. For instance, the effect of education on wages is half of a percentage point lower $(5.86 \%$ instead of $6.38 \%)$, the effect of age is one percentage point above for the first years (3.38\% instead of $2.27 \%)$, the wage discount of women is two percentage points lower (-11\%.instead of $9.02 \%)$.

We also estimate the recursive system for various sub-samples, but only present the coefficients of commute distance and the effect of one hour of commute on wages in Table 7.

\section{Implications}

An interesting implication of the model in Section 3.3 and in particular Proposition 1 is that the cost impact of commuting on wages is related to the bargaining power of workers. Indeed, a marginal increase in commuting cost for the worker (in terms of disutility) implies an increase in $\log$ wages that is proportional to $(1-\beta)$, that is the complement of workers's bargaining power to 1. However, we do not know the disutility cost of say, one hour commute for workers. We however know that most of the urban literature typically imputes this disutility to be half of the hourly wage, an estimate that is also exactly that given by the structural model of Van Ommeren et al. (2000). 
Table 6: Results of estimation

\begin{tabular}{|c|c|c|c|c|c|c|}
\hline \multirow[b]{2}{*}{ VARIABLES } & \multicolumn{3}{|c|}{ Recursive system equations } & \multicolumn{2}{|c|}{ Heckman model } & \multirow{2}{*}{$\begin{array}{c}\text { OLS } \\
\log w\end{array}$} \\
\hline & selection & $\log \mathrm{W}$ & log commute & selection & $\log \mathrm{W}$ & \\
\hline Children & $\begin{array}{c}-0.149 * * * \\
(0.02)\end{array}$ & & $\begin{array}{c}0.0191 \\
(0.01)\end{array}$ & $\begin{array}{c}-0.151 * * * \\
(0.02)\end{array}$ & & \\
\hline Any child $<3$ & $\begin{array}{c}-0.269 * * * \\
(0.05)\end{array}$ & & $\begin{array}{c}0.214 * * * \\
(0.04)\end{array}$ & $\begin{array}{c}-0.223 * * * \\
(0.05)\end{array}$ & & \\
\hline Married*wom. & $\begin{array}{c}-0.475^{* * * *} \\
(0.05)\end{array}$ & $\begin{array}{c}0.00840 \\
(0.02)\end{array}$ & $\begin{array}{c}0.0696 \\
(0.04)\end{array}$ & $\begin{array}{c}-0.476^{* * * *} \\
(0.05)\end{array}$ & $\begin{array}{c}0.0281 \\
(0.02)\end{array}$ & $\begin{array}{c}-0.0210 \\
(0.02)\end{array}$ \\
\hline Woman & $\begin{array}{c}-0.581 * * * \\
(0.05)\end{array}$ & $\begin{array}{c}-0.111 * * * \\
(0.02)\end{array}$ & $\begin{array}{c}0.113 * * * \\
(0.04)\end{array}$ & $\begin{array}{c}-0.603 * * * \\
(0.05)\end{array}$ & $\begin{array}{c}-0.0902 * * * \\
(0.02)\end{array}$ & $\begin{array}{c}-0.133^{* * * *} \\
(0.02)\end{array}$ \\
\hline Small area & & & $\begin{array}{r}0.0107 \\
(0.04)\end{array}$ & & & \\
\hline Rural area & & & $\begin{array}{c}0.0724 * * \\
(0.04)\end{array}$ & & & \\
\hline Outskirts Paris & & & $\begin{array}{c}0.159 * * * \\
(0.06)\end{array}$ & & & \\
\hline Age & $\begin{array}{c}0.169 * * * \\
(0.02)\end{array}$ & $\begin{array}{c}0.0338^{* * * *} \\
(0.01)\end{array}$ & $\begin{array}{c}-0.0483 * * * \\
(0.01)\end{array}$ & $\begin{array}{c}0.172 * * * \\
(0.02)\end{array}$ & $\begin{array}{c}0.0227 * * * \\
(0.01)\end{array}$ & $\begin{array}{c}0.0371 * * * \\
(0.01)\end{array}$ \\
\hline Age squared & $\begin{array}{c}-0.00220 * * * \\
(0.00)\end{array}$ & $\begin{array}{c}-0.000337 * * * \\
(0.00)\end{array}$ & $\begin{array}{c}0.000649 \text { *** } \\
(0.00)\end{array}$ & $\begin{array}{c}-0.00223 * * * \\
(0.00)\end{array}$ & $\begin{array}{c}-0.000203 * * \\
(0.00)\end{array}$ & $\begin{array}{c}-0.000399 * * * \\
(0.00)\end{array}$ \\
\hline French & $\begin{array}{c}0.304 * * * \\
(0.07)\end{array}$ & $\begin{array}{c}0.0435 \\
(0.04)\end{array}$ & $\begin{array}{c}-0.254 * * * \\
(0.07)\end{array}$ & $\begin{array}{c}0.312 * * * \\
(0.07)\end{array}$ & $\begin{array}{c}-0.0100 \\
(0.04)\end{array}$ & $\begin{array}{c}0.0457 \\
(0.04)\end{array}$ \\
\hline School years & $\begin{array}{c}0.0326 * * * \\
(0.00)\end{array}$ & $\begin{array}{l}0.0586^{* * * *} \\
(0.00)\end{array}$ & & $\begin{array}{c}0.038 * * * \\
(0.00)\end{array}$ & $\begin{array}{l}0.0584 * * * \\
(0.00)\end{array}$ & $\begin{array}{c}0.0638 * * * \\
(0.00)\end{array}$ \\
\hline Non lab. income & $\begin{array}{c}0.000587 * * * \\
(0.00)\end{array}$ & & & $\begin{array}{c}0.000628^{* * * *} \\
(0.00)\end{array}$ & & \\
\hline Non lab. inc. sq. & $\begin{array}{c}-6.88 \mathrm{e}-08 * * * \\
(0.00)\end{array}$ & & & $\begin{array}{c}-7.41 \mathrm{e}-08^{* * * *} \\
(0.00)\end{array}$ & & \\
\hline Dur occ. renter & $\begin{array}{c}0.0110 * * * \\
(0.00)\end{array}$ & & $\begin{array}{c}0.00251 \\
(0.00)\end{array}$ & $\begin{array}{c}0.0134^{* * * *} \\
(0.00)\end{array}$ & & \\
\hline Dur occ. owner & $\begin{array}{c}0.000850 \\
(0.00)\end{array}$ & & $\begin{array}{c}-0.00742 * * \\
(0.00)\end{array}$ & $\begin{array}{c}-0.000299 \\
(0.00)\end{array}$ & & \\
\hline Work experience & & $\begin{array}{l}0.0104 * * * \\
(0.00)\end{array}$ & & & $\begin{array}{c}0.0107 * * * \\
(0.00)\end{array}$ & $\begin{array}{l}0.0129 * * * \\
(0.00)\end{array}$ \\
\hline Commute hours & & $\begin{array}{c}0.327 * * * \\
(0.04)\end{array}$ & & & $\begin{array}{c}0.0962 * * * \\
(0.03)\end{array}$ & $\begin{array}{c}0.103 * * * \\
(0.03)\end{array}$ \\
\hline Commute sq. & & $\begin{array}{c}-0.0418^{* * * *} \\
(0.01)\end{array}$ & & & $\begin{array}{c}-0.0121 \\
(0.01)\end{array}$ & $\begin{array}{c}-0.0133^{*} \\
(0.01)\end{array}$ \\
\hline Region dummies & yes & yes & yes & yes & yes & yes \\
\hline Occupation dummies & no & no & yes & no & no & no \\
\hline Industry dummies & no & no & yes & no & no & no \\
\hline Firm size dummies & no & no & yes & no & no & no \\
\hline rho_sw & $\begin{array}{c}-0.246^{* * * *} \\
(0.07)\end{array}$ & & & $\begin{array}{c}-.652 * * * \\
(.042)\end{array}$ & & \\
\hline rho_sd & $\begin{array}{c}-0.70 * * * \\
(0.04)\end{array}$ & & & & & \\
\hline rho_wd & $\begin{array}{c}-0.234 * * * \\
(0.05)\end{array}$ & & & & & \\
\hline Observations & 8665 & & & 8665 & & 2298 \\
\hline
\end{tabular}


If we use this as a benchmark value and plug it into the wage equation, we can see that the wage effect of one hour of commute should be $(1-\beta) / 2$. Indeed, we have that the wage increase due to $\Delta d=1 h$ of commute compared to no commute is given from that proposition by

$$
\frac{\Delta w}{\Delta d}=(1-\beta) \frac{\Delta C}{\Delta d}
$$

Stating that $\Delta C=w / 2$ when $\Delta d=1$, we have therefore that

$$
\Delta w / w=(1-\beta) / 2
$$

which we can therefore identify from the estimated wage equation. It follows that, from the wage impact of one hour of commute, call it $\lambda$, we obtain an estimate of the bargaining power of workers given by

$$
\beta=1-2 \lambda
$$

We can apply this formula to the results of Table 7 and additional estimates in different sub-samples which we do not fully report for the sake of brevity (we only report the relevant coefficients). The findings indicate that the effect of distance on wages is heterogenously distributed among demographic groups, and much larger for women than for men.

Table 7: Estimates of Bargaining Power

\begin{tabular}{llcccccc}
\hline \hline Sample & All & Men & Women & $\begin{array}{c}\text { Married } \\
\text { women }\end{array}$ & $\begin{array}{c}\text { Mrrd women } \\
\text { with kids }\end{array}$ & $\begin{array}{c}\text { All women } \\
\text { with kids }\end{array}$ & $\begin{array}{c}\text { All women } \\
\text { with kids }<3 \text { yo }\end{array}$ \\
\hline Coefficient on: & & & & & & & \\
Commute dist. & 0.327 & 0.146 & 0.500 & 0.529 & 0.476 & 0.487 & 0.577 \\
$\begin{array}{l}\text { Commute dist.sq. } \\
\quad-0.042\end{array}$ & -0.015 & -0.078 & -0.075 & -0.053 & -0.069 & -0.085 \\
$\quad \begin{array}{c}\text { Wage impact } \\
\text { of 1h commute }\end{array}$ & 0.285 & 0.131 & 0.421 & 0.454 & 0.423 & 0.417 & 0.492 \\
Implied $\beta$ & 0.430 & 0.739 & 0.157 & 0.091 & 0.155 & 0.165 & 0.016 \\
\hline
\end{tabular}

The bargaining power of the total sample population is 0.43 , however, for men it is 0.739 while for women it is 0.157. Married women have lower bargaining power, 0.091. The lowest bargaining power is for women with young children present (less than age 3), 0.016 . 


\section{Commuting and fatigue}

The data set also allows us to examine how commuting might affect fatigue, defined as a binary variable taking value 1 if the respondent reports fatugue from commuting and zero otherwise. It is also indirectly a mesure of productivity if the worker's efficiency at work depends on how tired she/he is from commuting. Table 8 shows these results. First, Column 1 shows that commute distance has a strong and positive effect on fatigue, but the effect is not concave, but convex: longer commutes have a lower marginal effect on the fatigue probability. This may be due to the fact that longer commutes can be organized in a more convenient way, or due to endogenous shifting of commute modes, but the concavity can be found even controlling for modes or for a given commuting mode. In Column 1, we report the regression for the sample with both parttimers and full-time workers. Column 2 restricts the sample to full-time workers. Column 3 adds up a linear and quadratic term in hours worked that turn out not to be significant. The same is true in Column 4 with only a linear term. Column 5 and subsequent columns investigate the effect of commute modes. In Column 5, we can see that, compared to the reference (walk), all modes are associated with more fatigue, even conditioning on commute distance. Based on the most frequent commuting modes (car, metro and bus) we observe concavity in the effect of commute time on fatigue (see Columns 6 to 8 ).

\section{Conclusion}

This paper examines the effect commute distance has on labor markets. Reservation strategies in distance and in wages are basically the reciprocal of each other since there exists a reservation wage for each commute distance and a reservation distance for each offered wage. The estimate of Mincerian wage equations can usefully exploit information on commute distance in order to improve the quality of selection equations. We show that these estimates imply a lower positive impact of age ( +1 p.p. for the linear coefficient on age), a stronger wage penalty of women in wages (-2 p.p.), as well as an increase in the returns to schooling (+0.5 p.p.). The wage impact of 


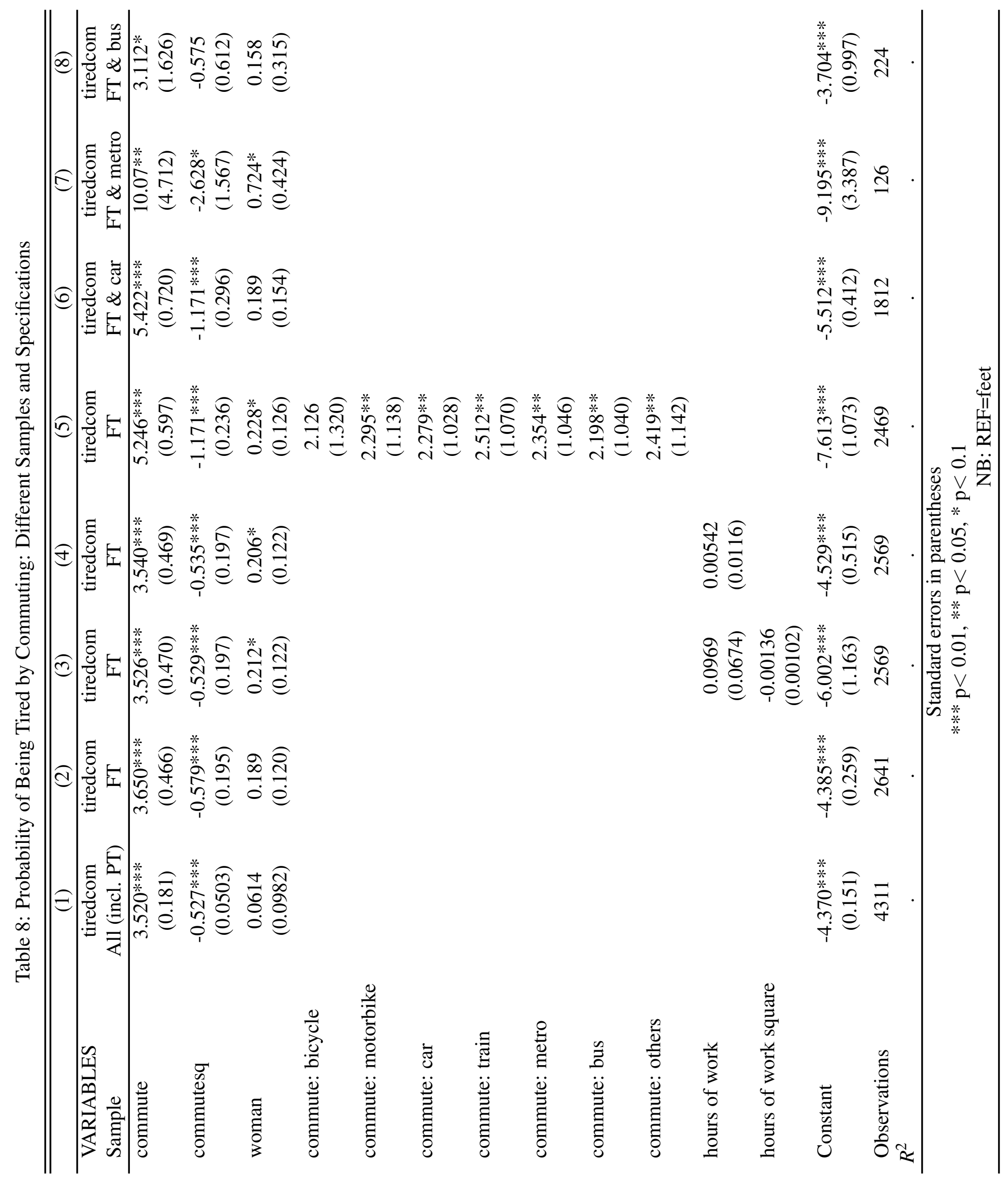


one hour of commute is estimated to be $29 \%$, while conventional estimates underestimate it by a factor 3 . 


\section{References}

Bloemen, Hans, and Stancanelli, Elena. "Individual Wealth, Reservation Wages, and Transitions into Employment.” Journal of Labor Economics 19 (April 2001): 400-439.

Diamond, Peter A. “Mobility Costs, Frictional Unemployment, and Efficiency.” Journal of Political Economy 89 (1981): 798-812.

Diamond, Peter A. "Wage Determination and Efficiency in Search Equilibrium.” Review of Economic Studies 49 (1982): 217-227.

Gaumont, Damien, Schindler, Martin, and Wright, Randall. "Alternative Theories of Wage Dispersion.” European Economic Review 50 (2006): 831-848.

Gautier, Pieter, and Zenou, Yves. "Car Ownership and the Labor Market of Ethnic Minorities." (2008). IZA Discussion Paper No. 3814.

Lucas, Jr., Robert E., and Prescott, Edward C. "Equilibrium Search and Unemployment.” Journal of Economic Theory 7 (1974): 188-209.

Manning, Alan. "The Real Thin Theory: Monopsony in Modern Labour Markets." Labour Economics 10 (2003): 105-131.

Rupert, Peter, and Wasmer, Etienne. "Time to Move and Aggregate Unemployment." (2008). Working Paper, University of California, Santa Barbara.

Stigler, George. “The Economics of Information.” Journal of Political Economy 69 (1961): 213225.

Van den Berg, G.J., and Gorter, C. "Job Search and Commuting Time." Journal of Business and Economic Statistics 15 (1997): 269-281.

Van Ommeren, Jos, Van den Berg, Gerard, and Gorter, C. "Estimating the Marginal Willingness to Pay for Commuting.” Journal of Regional Science 40 (2000): 541-563. 
Wasmer, Etienne, and Zenou, Yves. "Does Space Affect Search? A Theory of Local Unemployment." Labour Economics 13 (2006): 143-165. 